Frank Jansen* and Ninke Stukker

\title{
A drift toward direct structures in Dutch direct mail sales letters
}

\begin{abstract}
Dutch direct mail sales letters have traditionally had an indirect structure. In such a format, the transactional proposition is presented late in the letter in order to maximize the possibility that the readers will pay attention to, be interested in, and feel motivated to consider the proposition in a positive way. Nowadays, this type of direct mail letter seems to compete with letters of a different structure, one that is more direct, that has a transactional proposition earlier in the text. Two diachronic corpus studies were conducted to see whether this impression could be corroborated. Both studies give some evidence of a drift toward a more direct structure. Some tentative explanations are offered.
\end{abstract}

Keywords: direct mail sales letters, directness, text structure, AIDA formula, genre conventions, diachronic development of discourse genres

DOI 10.1515/text-2014-0017

\section{Introduction}

Direct mail sales letters belong to the most extensively studied discourse genres. In view of their ubiquity, their peculiar style, and their relevance for both text linguists and copy writers, it is not difficult to see why.

Genre is commonly defined as "a class of communicative events, the members of which share some set of communicative purposes. These purposes are recognised by the expert members of the parent discourse community and thereby constitute the rationale of the genre. This rationale shapes the schematic structure of the discourse and constraints choice of content and style" (Swales 1990:58).

Bhatia (2004) discerns clusters of genres with a common purpose, which he calls "genre colonies." Among these Bhatia (2004) discusses the promotional

*Corresponding author: Frank Jansen: Utrecht Institute of Linguistics OTS, Universiteit Utrecht, The Netherlands. E-mail: F. Jansen1@uu.nl

Ninke Stukker: Center for Language and Cognition Groningen, Groningen University, The Netherlands. E-mail: N.M.Stukker@RUG.nl 
genre colony. It comprises several persuasive genres, including that of the sales letters, which can be characterized by the sender's intention to convince the reader to comply with his/her offer of a product or service. A subgenre of the sales letter is the direct mail sales letter (see also Bhatia 1993; Upton 2002; Gillaerts and Gotti 2005). While the sales letter is a letter from an individual person to another person, the direct mail letter is a kind of mass communication. Letters of this subgenre are printed in thousands of copies; only the name of the addressee and the salutation are personalized.

Genres are identified by their linguistic characteristics, but also by the specific way the contents of texts belonging to a genre are organized - their structure. Most genre analysts consider texts as goal-directed communicative events consisting of consecutive communicative acts or moves which together fulfill the purpose of the text (Van Dijk 1988; Swales 1990; Martin 1992; Bhatia 1993; Biber et al. 2007). In some functional genres no hierarchical order between the principal moves holds, for example an exhibition catalogue. In other genres one move is clearly more important than others, because it comprises the central message of the text, while the purpose of the additional moves is to support the central move; an example is the application letter, in which the move expressing the applicant's interest in the job is obligatory (Henry and Rosenberry 2001; Khan and Tin 2012).

The position of this "main move" is clearly genre dependent. ${ }^{1}$ In some genres it is nearly obligatory to begin with the main move - these genres have a direct structure. An example is the letter of condolence, which begins with the condolences. Others present their main move at the end, resulting in an indirect structure. An example is the "and the winner is: ..." speech of the Oscar ceremony. In other genres the position of the main move is somewhere in between these two extremes, for example in direct mail sales letters.

Indirectness is traditionally considered the main principle guiding the organization of the moves of direct mail sales letters.

The first model attested addressing the issue of the structure of direct mail sales letters is known as the AIDA-formula, an acronym of Attention, Interest, Desire, and Action, referring to the consecutive steps the reader of a direct mail letter should go through. According to Strong (1925), the ideas underlying the formula were developed by the American psychologist and advertisement advocate

1 As far as we know there is no standard terminology for what we call "main move." In rhetorical structure theory the concept is called "central nucleus" (Abelen et al. 1993). Beamer (2003), working in a speech act theory framework, uses the terms "principal speech act" and "head act" for the same concept. Wang (2010) uses the term "main point." 
E. St Elmo Lewis, who introduced the formula in an address that was never published (see also Riedl 1992). ${ }^{2}$

The first task of a copywriter composing a direct mail sales letter is to get the Attention of the reader. Only then, will the reader be open to the letter's content. Most of the attention-grabbing work is done by Picturing the problem using text and images. Next, the copywriter will try to awaken the Interest of the reader; i.e., by describing a familiar problem for which the company of the sender Promises a solution in the form of a service or product. The following move is meant to stimulate the Desire of the reader. Here, the characteristics of the offer are described in an elaborate way that Proves that the offer is adequate, by presenting the details of the offer and the compensation that is expected in return (see also Section 4.2.1). Therefore Desire is considered the main move. Finally, when the reader is already convinced that he will accept the offer, he is pushed into Action to close the deal.

This indirect AIDA structure has been very influential in the United States (Strong 1925). This influence remained after the first quarter of the twentieth century (see, for example, Poe 1994; White and Woods 1996). The same applies for the Dutch language (De Jong 2002; Janssen 1996; Van Ommen and Kuppenveld 1991). The corpus study by Jansen (1992) substantiates the predominance of AIDA structures in Dutch direct mail letters.

Do Dutch direct mail sales letters in the beginning of the twenty-first century still have an indirect structure? In spite of the persistence of the AIDA principle in textbooks as a genre model, its adequacy for characterizing the actual structure of the genre may be questioned. The speed of communication and the amount of available information have dramatically increased. In addition, development of (digital) new media has promoted directness as a style of communication, and thanks to more widespread and better education, genre literacy has increased. It is a well-known fact that genres tend to adapt to the evolving needs of their users.

In this paper, we present the results of two corpus investigations suggesting that this is what is happening to the genre of direct mail sales letters. The genre is on the move toward a more direct structure (Sections 4 and 5). In Section 6, we offer a tentative explanation for the gradual diachronic shift observed. First, however, we will elaborate our concept of "directness of communication" somewhat further in Section 2 and present our research question in Section 3.

2 The AIDA formula has a parallel in a model of the direct mail sales letter that is oriented to the text segments themselves: the Picture, Promise, Prove, Push formula (De Jong 2002; Schuurs and De Groot 2008). 
The methodological significance of the study presented here concerns its use of the position of the main move, instead of presence and order of all moves, to characterize structural changes in a genre. The theoretical significance is that the results call into question the commonly accepted idea that direct mail sales letters have an indirect structure. Instead the structure of this genre seems to be liable to some dynamism.

\section{Indirect and direct structures}

\subsection{Why indirect structures are attractive in general}

When direct and indirect structures are considered as minimal pairs in an opposition, the two do not seem to be equivalent. The direct structure is marked in relation to the indirect structure. In genres where the position of the main move is variable, there are more moves before the main one than after it. This holds for spoken and written genres.

The overall structure of most face-to-face conversations is indirect. When a sender makes contact with a receiver they start a joint project for which both are responsible (Clark 1996). They need to establish common ground by way of greetings and other preparatory turns before they can perform the main move that was the purpose of the conversation. The preference for indirectness is also found on the conversational micro-level (see Schegloff [2007] for a discussion). In conversational analysis, conversations are considered a series of adjacency pairs, like invitation-acceptance (or declining), that can be considered as a main move in combination. These adjacency pairs are sometimes preceded by pre-expansions and/or followed by post-expansions, which prepare for and comment on the main move, respectively. Pre-expansions turn out to be more diverse and more elaborate than the post-expansions. Schegloff (2007) distinguishes between pre-announcements, pre-invitations, pre-offers, pre-requests, and even prepre-sequences, while there is no need for a similar typology of post-sequences. Furthermore, the pre-sequences are often very elaborate - Schegloff (2007: 53) presents an example of 79 protocol lines before a request is formulated - while post-expansions are rather minimal. From the perspective of the position of the adjacency pairs forming the main move of this common project, this means that they occur rather late.

Written messages are also mainly indirect. Consider the traditional letter, where there are more conventional elements before the body text (logo, sender's address, addressee's name and address, subject line, place, date, salutation) than after the body text (salutation, signature, name and occupation of the 
sender). This asymmetry is quite functional, as all of the first mentioned elements are meant to establish common ground. As for the body text of letters, Pilegaard's (1997) corpus analysis of business letters covering an entire commercial negotiation track is relevant. He finds that the letters in the early stages of this track, including sales letters, often start with so-called positive politeness strategies: showing interest in the receiver and engaging in small talk (Brown and Levinson 1987). With expressions comprising these strategies in the beginning, the main move is automatically stacked down toward the middle or the end of the letter.

\subsection{The advantage of indirectness in direct mail sales letters}

What is the effect of the indirect structure for direct mail sales letters? The reader's initial attitude toward a transactional proposal is ambivalent at best. On the one hand, s/he will feel attracted to the product or service on offer because of its inherent characteristics, or because s/he can use it to solve a problem. At the same time, the reader will be suspicious because the product is new, unfamiliar to him/her, and perhaps not worth the price. These characteristics make the transactional proposal a Face Threatening Act in the terminology of politeness theory (Brown and Levinson 1987). Especially the negative face of the reader, the idea that $\mathrm{s} /$ he is autonomous in deciding how to spend his/her money, is somewhat injured. Beginning with the transactional proposition would, therefore, cause embarrassment to the reader. The risk is high that $\mathrm{s} /$ he would stop reading the letter too soon and abandon consideration of the proposal altogether. The indirect structure prevents this embarrassment by carefully preparing the reader for the transactional proposition.

In the AIDA model as an account of the structure of direct mail letters the moves and their order are presumably modelled after the oral dialogic genre of sales talk. The clearest example of this approach is Vögele's (1992 [1983]). The subtitle of his book reads The dialogue method of direct written sales communication. His point of departure is the sales talk, a dialogue wherein a sales representative tries to persuade a prospective client to accept an offer. In such a dialogue, the client has all kinds of questions about the offered product or service, and it is the task of the representative to answer them in a way that satisfies the client. Vögele models the direct mail letter as a series of answers in advance of questions that will come up as receivers read the letter. The aim of the copywriter is to present answers eliciting a (silent) yes from the reader, which culminates in a big yes to the transactional proposition.

The AIDA structure is nothing other than a transposition of these strategies to written text. The writer brings the reader to the acceptation in a step-by-step way. 
The persuasion process in the talk takes some time, so it is no problem that the text aiming at the same goal also becomes longer.

Empirical support of the hypothesis that direct mail letters generally have an indirect structure can be found in various corpus studies. Most studies are inspired by Bhatia's (1993: 53) move analysis of one sales letter. Corpus analysts Joergensen (2005) and Cheung (2009) have proposed adaptations of Bhatia's moves scheme, thereby enhancing the indirect character of the overall structure. Joergensen (2005) proposes an alternative scheme of seven moves, with the transactional proposition in moves 5 and 6. Cheung (2009) extends the scheme to 10 moves that comprise, in their turn, 36 steps. Although she never refers to the price in her typology, the most probable position of the transactional proposition is in move 5, step 1 providing gifts and discounts. As this is the 28th step (of 36) we conclude that her move scheme is indirect. Of special interest is the diachronic study by Zhu (2000), who analyses the changes in several sales genres during the socio-political transformation of mainland China in the last fifty years. We conclude from his examples that the structure of sales letters has become more direct.

\subsection{Disadvantages of the indirect structure}

The motivations for the successive moves given in the previous section can be considered implicit arguments for the indirect structure. However, the indirect structure has some disadvantages as well: it may not serve the needs of a reader who has too little time or is too proficient to feel embarrassed by any proposition.

The AIDA structure is perhaps less effective because the transactional proposition typically appears in the second half of the letter. This corroborates the risk that the reader will have already quit reading the letter before reaching the proposal. Furthermore, if the proposal is concealed in the midst of other sentences, a reader may have difficulties recognizing the transactional proposal.

Second, even if the readers are able to find the transactional proposition, its late introduction may be less efficient because it presumes an unrealistic amount of patience on the reader's side.

For other readers the cautious presentation may be unnecessary. They are aware of the commercial intentions at the outset, because they recognize the sender and remember experiences with previous letters, or because a slogan on the envelope gives away some features of the offer. They may be frustrated when they have to read almost the entire letter until they find what they want.

Finally, when we assume that many receivers are experienced readers of functional text genres, we expect that they have learned from earlier reading experiences that an indirect structure is a foreshadowing of bad news. Those 
readers will transfer the negative connotation of those messages to the direct mail letter at hand.

These disadvantages of an indirect structure may have induced the development of a more direct way of structuring direct mail letters. We will take up these matters in the discussion (see Section 6.3).

\section{Research question}

In the previous section, a case has been made for the existence of an alternative for the traditional indirect structure based on the AIDA formula. It depends on the frequency of letters with this alternative structure whether a drift toward more direct text structures can be proven. This leads to the following research question:

To what extent have the structural conventions of Dutch direct mail letters changed from indirect into more direct structures?

\section{Study 1: a diachronic analysis of the position of the transactional proposal in Dutch direct mail letters, 1989-2001}

\subsection{Introduction}

In our first corpus study, we compared Dutch direct mail letters sent during the late 1980s with letters sent around the start of the new millennium. In Section 4.2, we will give the details of the corpus, the methodology of scoring the transaction, and its validation. In Section 4.3, the results are presented, followed by a conclusion in Section 4.4.

\subsection{Material and method}

\subsubsection{Material: the letters in the corpora}

We selected two corpora consisting of fifty direct mail letters each (see Table 1). All letters were printed on paper and sent by mail. All letters satisfied the condition that the body text comprised a passage that presented the transactional 
Table 1: Characteristics of the letters in the two corpora

\begin{tabular}{lll}
\hline & Old letters & Recent letters \\
\hline Date of issue & $1989(2.3)$ & $2001(1.1)$ \\
Length (sentence) & $18.5(8.1)$ & $17.5(8.7)$ \\
Type of transaction & & \\
Subscriptions & 9 & 9 \\
Products & 25 & 19 \\
Services & 16 & 22 \\
\hline
\end{tabular}

proposition, the expression where the reader for the first time could gather a more or less complete idea of the deal the issuing company proposed to him/her.

Identification of the transactional proposition. As far as the wording of the transactional proposition is concerned, there are three variants. The first is the explicit mention of the purchase, which makes the transaction proposition easily recognizable:

(1) Therefore, Eyeworks has a unique proposal for you: until June 15, you can acquire an extra pair of lenses for a sharply reduced price. You will not pay f378 for your lenses, but only f278.

The transactional proposition here is: pay $\mathrm{f} 278$, and get two pairs of contact lenses.

In the second variant, the writer makes an allusion to the purchase by using vague paraphrases of purchasing. See, for example, how a cat food company introduces a customer loyalty campaign:

(2) (a) The special Sheba celebration menu will not be sold in stores. (b) Of course, you can still go there if you want to surprise your cat with the other Sheba varieties. (c) Do not forget to keep the tabs from the covers. (d) Use these to get a set of twelve exclusive greeting cards with pictures of kittens and cats for a special prize at home.

The sender assumes that readers can build the following mental representation of the transactional proposition: I receive a set of pictures, when I buy several cans of cat food, collect the tabs and send them in together with some money. Another way to vaguely paraphrase the transactional proposition is not to mention the price to be paid, but only the amount of discount: 
(3) To begin with, we exclusively offer no less than a $30 \%$ discount on ladies fashion to our regular customers.

The content of the transactional proposition here is: Buy a piece of ladies wear and pay $70 \%$ of the original price.

In the third variant, the writer presents the product and its advantages without mentioning any of the client's obligations:

(4) With the Guarantee policy of ABLA, you will get high guaranteed interest (7.3\% now) while you can save tax-free during the entire term of twenty years.

The principal obligation of the reader and the prospective ABLA client remains implicit: invest a sum of money.

In most direct mail letters, the transactional proposition is different from the Action passage (the second $A$ of AIDA) where the reader is urged to take some communicative steps in order to make the transaction effective. To appreciate the difference between the two, see the next example where (a) is the transactional proposition and (c) the Action passage.

(5) (a) And that you can still subscribe to Football with full confidence for the attractive price of only f11, - until January 1, 1988. (b) However, this is the last time that we can send Football as an introductory offer and the last chance for you to profit from the special introductory offer for members of the football association: until January 1 Football in your mailbox for only "a team of eleven" florins. (c) The only thing you have to do is to send the attached completed form to your bank.

The purpose of (a) is to reassure the reader, an act of speech that belongs to the persuasive category: the reader can remain a subscriber of the magazine. Besides this, (a) is informative about the conditions the reader has to fulfill to remain a subscriber. The purpose of (c) is mainly instructive. The main purpose of the passage is to spell out the actions the reader has to perform in order to let the publisher know that s/he wants to remain a subscriber. Although their strong persuasive undertone makes (a) and (c) similar, they differ in that the transactional proposition (a) is oriented to the client's decision to accept the offer, but the Action passage (c) is oriented to one or more of the preparatory conditions for closing the deal. As these instructional action passages typically occur at the end of the body text and do not belong to the main move, we refrained from analyzing their position. 
The two corpora were balanced for text length, genre, type of company, and transaction type as indicated below.

Text length. In Table 1, the length of the letters in the two corpora is displayed in terms of their mean number of sentences. The format difference between old and recent letters is not significant $(F(1,98)=0.34 ; p=0.56)$.

Genre. Only sales letters were incorporated because in this genre the two components of the transactional proposal are rather evident. So, fundraising letters and sweepstakes were excluded. All letters were mailed as an independent commercial action. This means that all letters preparing the addressee for an important successive letter or warning and reminding messages were also excluded.

Type of transaction. In both corpora we selected letters from similar branches. Heavy mailers such as banks, insurance companies, and mail order firms are represented, as well as incidental mailings from small-scale business companies. The economic dynamism of take-overs and bankruptcies prohibited a one-on-one correspondence between the letters in the old and recent groups. We selected letters with similar types of transactions such as subscriptions, products, and services. Table 1 demonstrates that this was only successful to a certain degree: in the old category, the proportion of letters offering a material product is relatively high; in the recent category, this occurs for (financial) offers. This imbalance has no effect on the results $(p>0.05)$.

Date of issue. The only difference between the two corpora that we implemented consciously is the date the letters were issued. The corpus with older letters held letters from around 1989 but no later than 1993. The corpus with more recent letters date from around 2002, but no earlier than 2000 (see Table 1).

\subsubsection{Scoring method and reliability}

As our research question concerns a difference between relative positions of the transactional proposition in the overall text organization, we used relative position as a measure to compare the "old" and the "new" letters for directness. Therefore, first, all sentences in the body text (the text between the salutation and the closing formula) were assigned a ranking number. Then the transactional proposition was isolated, and finally its relative position in the text of the letter was computed by dividing its ranking number by the total number of sentences of the letter. 
The isolation and scoring were initially done by a student of the Masters in Communication Studies (Mulder 2003). In about ten cases in which she felt insecure about her decision, she made her choice after discussing the matter with the authors.

As the isolation of the transactional proposition makes an appeal on interpretation on the one hand, and the student and her supervisors knew about the hypothesis of increasing directness and they could easily deduce the issue date of the letters from their layout and content on the other hand, their scoring might be biased. Therefore, an experiment was done to test the reliability of the initial scoring (Oonk 2004). Four students of the Masters in Communication Studies who did not have any expertise in direct mail and did not know about the directness hypothesis were individually requested to find the transactional proposition. They were first given rather elaborate instruction about the transactional proposition and its diverse appearances in a series of six letters, which were, of course, other than those in the corpus. After that, they were presented with the letters of the two corpora in a random order. The inter-rater reliability was acceptable $(r=0.81)$.

\subsection{Results}

In Table 2, the mean positions (and standard deviations) of the transactional proposition in the older letters and the more recent letters are presented.

Table 2 demonstrates a considerable difference (of 16\%) in the expected direction between the old and the recent letters. The difference is statistically significant $\left(F(1,98)=22.2 ; p<0.001, \eta^{2}=0.19\right)$.

Table 2: Mean position (and standard deviation) of the sentence with the transactional proposal (Minimum $=0$ [proposition in first sentence]; maximum $=1$ [proposition in last sentence])

\begin{tabular}{lll}
\hline & Old letters & Recent letters \\
\hline Transactional proposal & $0.62(0.28)$ & $0.46(0.24)$ \\
\hline
\end{tabular}

\subsection{Conclusion}

The answer to the Research Question is affirmative. The transactional proposition has shifted toward the beginning of the direct mail letters. However, the gap between the position in the old and recent letters is modest. We certainly do not see 
the transactional proposition jumping toward the opening lines of the letters. This conclusion has to be qualified in two respects: first, the stratified corpus that compares 50 versus 50 letters is rather small; second, the criteria for isolating the transactional proposition were rather broad: besides an explicit presentation of both sides of the transactional proposal, vague formulations of the obligations and even hints were incorporated. This may have made the complex concept of the transactional proposition elusive for the evaluators, which is corroborated by their less than perfect agreement. Therefore we decided to do a second study, on a larger corpus and with a slightly different methodology.

\section{Study 2: a refined diachronic analysis of the position of the transactional proposal in Dutch direct mail letters, 1989-2002}

\subsection{Introduction}

We decided to replicate the earlier corpus analysis with a few alterations. First, we enlarged the corpora by including as many direct mail sales letters as we could get hold of. We were not selective with regard to the format and the number of the letters. However, we were more demanding than in the first study where the criteria for the transactional proposition were concerned. Both the company's offer and the client's (financial) obligations had to be formulated explicitly. This means that only letters with transactional propositions of the explicit type (see example [1] in Section 4.2.1) were incorporated in this investigation.

The final change in the design has to do with the context of the transactional proposition. The core assumption of the traditional AIDA formula is that the reader should be well prepared when the transactional proposition finally appears, because he has already read about the product or service offered inside or outside the body text. We distinguished between three different types of preliminary information on the product or service offered that preceded the actual transactional proposal in the text: headings, introductions of the offer, and the relative order of transactional proposal and the argumentation for it.

Heading comprising the offer. One of the functions of a heading is that they identify the topic of the text following them (Lorch et al. 2011). Therefore, the first opportunity for the reader to get a hunch of the offer is in the heading, before $\mathrm{s} / \mathrm{he}$ 
begins reading the body text. ${ }^{3}$ Therefore we scored letters with a header that give an indication of the offer; for example: "Introduction chip card." Headers that expressed only a positive mood such as "Friendly spring delights" were left out.

Introduction of the offer. In most letters, an expression introducing the offer gives the reader a preliminary idea of the transaction proposed. This introduction of the offer is easy to discern from the transactional proposition. In the introduction of the offer, the sender presents only one-half of the transaction, namely what s/he has to offer to their clients; for example:

(6) Best wishes for the birth of Mirjam. Now that the first busy times with your little one have passed somewhat, we would like to inform you about the Postbank Giro Account and the Children's Profit Plan. (bold in original)

After the congratulatory introduction, the bank informs its client about the products offered. This introduction of the offer is a foreshadowing of the transaction.

Relative order of transactional proposition and arguments for the product or service offered. Finally, we investigated the relative order of the transactional proposition and the arguments for accepting that proposition, mostly attractive features of the product on offer. The order can be first arguments - then proposition or first proposition - then arguments. If the letter presented arguments and proposition in a different order, such as proposition in between the arguments or arguments not adjacent to the proposition, it was excluded from this specific part of the analysis.

\subsection{Material and method}

Again, only letters that were printed and sent by mail were incorporated. The old letters were issued before 1994; the recent letters were sent after 2000. The most important features of the letters in the two corpora are displayed in Table 3.

The difference in length between the old and more recent direct mailings turned out to be marginally significant $(F(1,250)=3.9, p=0.051)$. We do not expect that this tendency has an impact on the relative position of the transactional proposal.

3 Some of the letters had an envelope with a slogan comprising the offer. Although this feature influences the receiver's behavior considerably (De Wulf et al. 2000), we could not incorporate it in the investigation because in too many cases the envelope was missing. 
Table 3: Number, mean date, and length (and standard deviations) of the letters in the two corpora

\begin{tabular}{lll}
\hline & Old & Recent \\
\hline Number of letters & 103 & 149 \\
Mean year of issue & $1989(4.1)$ & $2002(2.2)$ \\
Mean length in sentences & $21(17)$ & $17(10)$ \\
\hline
\end{tabular}

The isolation of the introduction of the product or service offered, the transactional proposition, and its relative order with the arguments was first done by pairs of students of the Masters in Communication Studies who were uninformed of the hypothesis, as one of the assignments of a course in text analysis. Their scores were compared and checked by the first author who scored the headings by himself.

\subsection{Results}

In this section, we will first discuss the headings and then the respective positions of the introduction of the offer and of the transactional proposition.

In Table 4, the results of the analysis of headings comprising the offer are presented.

Table 4 demonstrates that the proportion of letters with a heading comprising the offer has increased between the old and the more recent time spans included in the study, which is a change in the expected direction $\left(X^{2}(1,241)=24.6\right.$, $p<0.001$ ). We also implemented the date of issue of the letters in both categories as a continuous variable in a regression analysis, and obtained the same result: $t(1,252)=-3,8 ; p<0.001, R^{2}=0.55$.

Table 5 summarizes our findings for the relative positions of the expressions introducing the offer and the transactional proposition.

The presentation of the offer has been shifted somewhat toward the beginning $\left(F(1,240)=9.6, p=0.002, \eta^{2}=0.04\right)$. The transactional proposition has shifted more dramatically in the expected direction $(F(1,250)=28.8, p<0.001$, $\eta^{2}=0.10$ ).

We also checked to see if there was a relation between the presence of a heading with the offer and the respective positions of the introduction of the offer and that of the transactional proposition; see Table 6.

Table 6 demonstrates that there is a relationship between the presence of a heading and the position of the kernel sentences in the letter. In letters with a 
Table 4: Proportion of letters with a heading comprising the offer in the two corpora

\begin{tabular}{lll}
\hline & No heading & Heading \\
\hline Old & $74(73 \%)$ & $28(27 \%)$ \\
Recent & $57(40 \%)$ & $84(60 \%)$ \\
\hline
\end{tabular}

Table 5: Mean position (and standard deviation) of the sentence with the offer and the transactional proposition

\begin{tabular}{lll}
\hline & Offer & Transaction \\
\hline Old & $0.29(0.23)$ & $0.74(0.19)$ \\
Recent & $0.21(0.18)$ & $0.59(0.24)$ \\
\hline
\end{tabular}

Table 6: Mean position (and standard deviations) of the offer and the transactional proposition in letters with and without a heading comprising the offer

\begin{tabular}{lll}
\hline & Offer & Transaction \\
\hline No heading & $0.30(0.22)$ & $0.70(0.22)$ \\
Heading & $0.18(0.15)$ & $0.59(0.22)$ \\
\hline
\end{tabular}

Table 7: Relative order of transactional proposition and the arguments for it

\begin{tabular}{lcc}
\hline Arguments & Before transaction & After transaction \\
\hline Old & $83(91 \%)$ & $8(9 \%)$ \\
Recent & $109(83 \%)$ & $23(17 \%)$ \\
Total & $192(86 \%)$ & $31(14 \%)$ \\
\hline
\end{tabular}

heading, the introduction of the offer comes earlier in the letter than in letters without a heading $\left(F(1,239)=16.8, p<0.001, \eta^{2}=0.08\right)$. The same is true for the position of the transactional proposition $\left(F(1,240)=16.8, p<0.017, \eta^{2}=0.07\right)$. There were no interactions with the year of issuing of the letter $(p>0.05)$.

Finally, we analyzed the relative position of the arguments for the product or service on offer relative to the transactional proposition; see Table 7.

The data in Table 7 suggest that the order "transactional proposition - arguments" seems to become more popular. As the position of the arguments after the transactional proposal makes the structure more direct, we are allowed to evaluate the statistical significance one-sidedly: $X^{2}=3.4, p_{\text {(one-sided) }}<0.05$. 


\subsection{Conclusion}

The results of the analysis of a somewhat bigger corpus of direct mail letters are in line with that of the smaller corpus. The transactional proposition has considerably shifted to the beginning, which means that the text structure of Dutch direct mail letters has become more direct. Besides this, there are more indications of increasing directness. First, a greater proportion of the letters is provided with a heading that reveals the offer. Second, if the product or service on offer is introduced in a separate passage, this has also shifted toward the beginning of the letter. Third, the relative order proposition-argumentation seems to become more frequent. And finally, the shrinking size of the letters can also be considered to be an indication of greater indirectness: the smaller the size of the letter, the greater the chance that the reader will identify the transactional proposition in the first glance.

In view of the limited time gap of 15 years between the corpora, we consider the rather modest differences of at most $15 \%$ to be indicative of an ongoing drift toward a direct structure.

An intriguing side result of the second study is that headings, offer, and transaction proposal are moving independently. We find no indication that copy writers implement the three in a concerted way; for example, by compensating for the absence of a heading with information about the offer by shifting the introduction of the offer toward a more advanced position.

\section{General conclusion and discussion}

\subsection{General conclusion}

In the last 15 years, the structure of Dutch direct mail letters has changed. First, headings with an indication of the offer have become more frequent. Second, the introduction of the product or service offered has shifted toward the beginning. Third, letters in which the arguments for the product or service are positioned after the transactional proposition have become more frequent than letters with the opposite order. Finally, and most importantly, the central move of a commercial direct mail letter, the transactional proposition, has also shifted to a position toward the beginning. As all these changes are in line with a more direct structure, the research question To what extent have the structural conventions of Dutch direct mail letters changed from indirect into more direct structures? can be answered as: yes, they do - to a considerable extent. 


\subsection{Limitations}

This conclusion has to be qualified by mentioning the most important limitations of the study. First, the object was a collection of Dutch letters. As it is not impossible that cultural differences play a role in these matters, we do not suggest that the results can be generalized automatically to other languages and cultures (see, for instance, Vergaro [2004] for a comparative move analysis of Italian and English sales promotion letters). We hope, however, that the results are an inspiration for other researchers to test whether the drift toward direct structures can be observed in other cultures.

Second, even the size of the larger corpus was rather small in comparison with some of the electronic corpora investigated by other text linguists, for example Cheung (2009). Third, the channel of the messages was limited to the classical letters on paper, sent by mail. Nowadays this genre gives way to the corresponding e-genre, e-direct mail, whose text structure is interesting in itself (Vermeulen 2001; Oranje 2006; Cheung 2008) and in comparison with traditional direct mail (see Section 6.3). Finally, the rather short time span between the mean dates of issue of the letters in the two corpora means that we cannot exclude the possibility that our results reflect temporary fluctuations, brought about by the frenzied world of copy writers.

\subsection{Discussion}

In this final section, we discuss three potential explanations for the drift toward direct structure we observed.

The first concerns a parallel and more general cultural development toward directness in Western society. This development can be attributed to the increasing speed of communication and the expanding amount of information we confront on a daily basis.

The acceleration of communication started in the sixteenth century and culminated in the so-called communication revolution in the twentieth century (see Behringer [2006] and the literature cited there). From that time on, the transportation time of messages within Europe has shrunk from weeks into seconds. This reduction has influenced our expectations about the time readers need to process the messages and react to them which, in turn, has put some pressure on the receiver to react as soon as possible.

The second development that calls for more directness is that the amount of information has increased dramatically during the past decades; this is especially the case for commercial messages such as direct mail letters (Akaah et al. 
1995). In order to cope with this information overload, members of modern society have developed more efficient and selective communication strategies. For example, Berkenkotter and Huckin (1995: Ch. 2) report that scientific journal articles underwent significant changes during the second half of the twentieth century (1944-1989), which they relate to the increased information pressure of their readers. They give evidence of a development in which experimental results have increasingly been foregrounded in titles, abstracts, introductions, and section headings. Berkenkotter and Huckin (1995: 42) argue that these changes allow the scientific journals' audience to access the most newsworthy information in the papers in a more selective and efficient manner.

Berkenkotter and Huckin draw an interesting parallel with the information structure of newspaper texts, in which a reader-based (1995: 32) design has long been the established convention. Newspaper texts typically display direct structure conventions in that the title yields up the most important news fact and the so-called inverted pyramid structure with a lead presents the news that is most relevant for the readers.

What the foregrounding of prominent information and the rigid structure do in expository discourse directed at a scholarly audience, and what the inverted pyramid structure does for the newspaper reader, the direct structure of persuasive messages does for the impatient, overloaded addressee.

Besides this general cultural explanation, we suggest also a cross-media one, which is linked to the first but does not coincide with it. The norms for an old medium are influenced by those of a related new medium. In his discussion of the changes in the way presidential addresses are reported in American newspapers, Schudson (1982) considers the news telegrams with their directness and terseness to be an important factor. Likewise, we suppose that a similar cross-media pattern of influence has been started with the introduction of e-direct mail, which is known to be more direct than the printed variety under scrutiny in the present paper (Vermeulen 2001; Cheung 2008; Oranje 2006). The prevalence of direct structure in e-direct mail can be attributed to the even greater time pressure of their receivers, but also to a factor sui generis: the fear of the sender that the transactional proposal "falls off the screen" and is not noticed by the reader who is too hurried to scroll down (Cheung 2008: 177). This second explanation is in line with an important principle of Internet communication, identified by the usability guru of Internet communication, Nielsen (see www.nngroup.com). ${ }^{4}$ Nielsen insists that the ideal text is scannable: the format and external structure are such

4 Jacob Nielsen, 1997. How users read on the web. http://www.nngroup.com/articles/how-usersread-on-the-web/ (accessed 6 July 2014). 
that a reader can extract the meaning of the text by a blink of the eye, as if $\mathrm{s} /$ he is looking at a picture. It speaks for itself that scannable texts are not only shorter than the dialogue text, but also more static. There is no room in it for letting the reader get acquainted with the writer and their product, or gradually developing a proposal.

Our third explanation capitalizes on the growing sophistication in the reader's "genre literacy." The assumption that gradual habituation to the idea that $\mathrm{s} /$ he has to comply with a commercial transaction makes the reader more susceptible to the offer makes sense, particularly in cases where the reader is rather naïve about (hard) selling methods. We may reasonably assume that Dutch readers (except perhaps children) have become more and more accustomed to direct mail letters, including the more seductive variants like sweepstakes. As soon as the reader has received a direct mail letter, s/he knows what the sender wants from them, so there is no longer a need for the sender to beat around the bush.

The three tentative explanations presented here are in line with findings that genres are dynamic entities - they are constantly developing, and changes in genre conventions are found to correlate with changes in the communicative needs of their users (see, for example, Berkenkotter and Huckin 1995: 4-7; Biber and Conrad 2009: Ch. 6).

The shift toward directness in direct mail letters would fit into this more general picture in a natural way. Just like the AIDA structure could be considered as the fulfillment of the reader's gradually developing wants (cf. Section 2.1); the more direct structure may be seen as a recent adaptation to the more modern reader's communicative needs.

As a hypothesis for further research, we would like to advance the idea that the increasing directness observed in our data is due to a gradual change with respect to the action scheme underlying the direct mail letter as a genre: from sales talk, a dialogic oral genre (see Section 2.2), toward the screen text, a visual genre. Another avenue of research is to answer the question of whether the reading public appreciates the growing directness of letters and other documents.

Acknowledgments: We thank Annelies Mulder and Dieneke Oonk who, as students, wrote theses for their Masters of Communication degrees relating to the investigations presented here; Ronny Boogaart for commenting on a previous version; and Huub van den Bergh for statistical assistance. 


\section{References}

Abelen, Eric, Gisela Redeker \& Sandra A. Thompson. 1993. The rhetorical structure of US-American and Dutch fund-raising letters. Text 13(3). 323-350.

Akaah, Ismael P., Pradeep K. Korgaonkar \& Daulatram Lund. 1995. Direct marketing attitudes. Journal of Business Research 34. 211-219.

Beamer, Linda. 2003. Directness in Chinese business correspondence in the nineteenth century. Journal of Business and Technical communication 17(2). 201-237.

Behringer, Wolfgang. 2006. Communications revolutions: A historiographical concept. German History 24(3). 333-374.

Berkenkotter, Carol \& Thomas N. Huckin. 1995. Genre knowledge in disciplinary communication: Cognition/culture/power. Hillsdale, NJ: Lawrence Erlbaum.

Bhatia, Vijay K. 1993. Analyzing genre: Language use in professional settings. London: Longman.

Bhatia, Vijay K. 2004. Worlds of written discourse. A genre-based view. London \& New York: Continuum.

Biber, Douglas \& Susan Conrad. 2009. Register, genre, and style. Cambridge: Cambridge University Press.

Biber, Douglas, Ulla Connor, Thomas A. Upton \& Budsaba Kanoksilapatham. 2007. Introduction to move analyses. In Douglas Biber, Ulla Connor \& Thomas A. Upton (eds), Discourse on the move, 23-41. Amsterdam \& Philadelphia: John Benjamins.

Brown, Pamela \& Stephen C. Levinson. 1987. Universals in language use: Politeness phenomena. Cambridge: Cambridge University Press.

Cheung, Ming. 2008. "Click here": The impact of new media on the encoding of persuasive messages in direct marketing. Discourse Studies 10.161-189.

Cheung, Ming. 2009. Sales promotion communication as social process and schematic structures. The Open Applied Linguistics Journal 2. 32-44.

Clark, Herbert. 1996. Using language. Cambridge: Cambridge University Press.

De Jong, Jaap (ed.). 2002. Zakelijk corresponderen [Business correspondence]. Groningen: Wolters Noordhoff.

De Wulf, Kristof, Janny C. Hoekstra \& Harry R. Commandeur. 2000. The opening and reading behavior of business-to-business direct mail. Industrial Marketing Management 29. 133-145.

Gillaerts, Paul \& Maurizio Gotti (eds). Genre variation in business letters. Bern: Peter Lang. Henry, Alex \& Robert L. Roseberry. 2001. A narrow-angled corpus analysis of moves and strategies of the genre "Letter of application". English for Specific Purposes 20. 153-167.

Jansen, Frank. 1992. Politeness phenomena in Dutch direct mail. In H. Pander Maat \& M. Steehouder (eds), Studies of functional text quality, 57-71. Amsterdam \& New York: Rodopi.

Janssen, Daniel (ed.). 1996. Zakelijke communicatie [Business communication]. Groningen: Wolters Noordhoff.

Joergensen, Poul E. F. 2005. The dynamics of business letters: Defining creative variation in established genres. In P. Gillaerts \& M. Gotti (eds), Genre variation in business letters, 147-178. Bern: Peter Lang.

Khan, Ajmal \& Tan Bee Tin. 2012. Generic patterns in application letters: The context of Pakistan. RELC Journal 43(3). 393-410. 
Lorch, Robert F., Julie Lemarié \& Rusell A. Grant. 2011. Three information functions of headings: A test of the SARA theory of signaling. Discourse Processes 48. 139-160.

Martin, J. R. 1992. English text: System and structure. Amsterdam \& Philadelphia: Benjamins.

Mulder, Annelies. 2003. Met de deur in huis [Getting straight to the point]. Utrecht: Doctoraalscriptie (MA thesis) Nederlandse Taal- en Letterkunde, Universiteit Utrecht.

Oonk, Dienke. 2004. Direct mail directer [Direct mail more direct]. Utrecht: Communication Studies Bachelor thesis, Utrecht University.

Oranje, Ilse. 2006. De structuur van direct-mailbrieven [The structure of direct mail letters]. Utrecht: Communication Studies Bachelor thesis, Utrecht University.

Pilegaard, Morten. 1997. Politeness in written business discourse: A textlinguistic perspective on requests. Journal of Pragmatics 28. 223-244.

Poe, Roy W. 1994. The McGraw-Hill handbook of business letters. New York: McGraw-Hill.

Riedl, R. 1992. AIDA-Formel. In G. Ueding (ed.), Historisches Wörterbuch der Rhetorik [Historical dictionary of rhetoric], vol. 1, 293-294. Tübingen: Max Niemeyer.

Schegloff, Emmanuel. 2007. Sequence organization in interaction. A primer in conversation analysis, volume 1. Cambridge: Cambridge University Press.

Schudson, Michael. 1982. The politics of narrative form: The emergence of news conventions in print and television. Daedalus 111(4). 97-112.

Schuurs, Uriël \& Elisabeth De Groot. 2008. Genreanalyse [Genre analysis]. In Peter Jan Schellens \& Michiel Steehouder (eds), Tekstanalyse [Text analysis], 162-197. Assen: Van Gorcum.

Strong, Edward K. 1925. Theories of selling. Journal of Applied Psychology 9(1). 75-86.

Swales, John M. 1990. Genre analysis. English in academic and research settings. Cambridge: Cambridge University Press.

Upton, Thomas A. 2002. Understanding direct mail letters as a genre. International Journal of Corpus Linguistics 7(1). 65-85.

Van Dijk, Teun A. 1988. News as discourse. Hillsdale, NJ: Lawrence Erlbaum.

Van Ommen, H. \& E. van Kuppenveld. 1991. Professionele bedrijfscommunicatie [Professional business communication]. Groningen: Wolters-Noordhoff.

Vergaro, Charles. 2004. Discourse strategies in Italian and English sales promotion letters. English for Specific Purposes 23. 181-207.

Vermeulen, Loes. 2001. Zo'n kans laat je toch niet liggen? Een onderzoek naar de tekststructuur van electronische verkoopbrieven [You do not despise such a chance, do you? An investigation of the text structure of electronic sales letters]. Utrecht: Doctoraalscriptie (MA thesis) Communicatiestudies Universiteit Utrecht.

Vögele, Siegfried. 1992 [1983]. Handbook of direct mail: The dialogue method of direct written sales communication. Hemel Hempstead: Prentice Hall International. Translation of Dialogmethode: Das Verkaufsgesprach per Brief und Antwortkarte, Landsberg am Lech.

Wang, Junhua. 2010. Convergence in the rhetorical pattern of directness and indirectness in Chinese and US business letters. Journal of Business and Technical Communication 24(1). 91-120.

White, Sarah \& John Woods. 1996. Do-it-yourself advertising, direct mail, and publicity. Holbrook, MA: Adams Publishing.

Zhu, Yunxia. 2000. Rhetorical moves in Chinese sales genres, 1949 to the present. Journal of Business Communication 37(2). 156-172. 


\section{Bionotes}

Frank Jansen is Assistant Professor in the Department of Communication Studies at Utrecht University. His main research interests are the structure and style of functional messages, especially in new media.

Ninke Stukker is Assistant Professor in the Department of Communication and Information Sciences at Groningen University. Her research interests include text linguistics and genre stylistics. 